\title{
Economic Power Dispatch with Discontinuous Fuel Cost Functions using Improved Parallel PSO
}

\author{
Belkacem Mahdad $^{\dagger}$, T. Bouktir*, K. Srairi* and M. EL. Benbouzid**
}

\begin{abstract}
This paper presents an improved parallel particle swarm optimization approach (IPPSO) based decomposed network for economic power dispatch with discontinuous fuel cost functions. The range of partial power demand corresponding to the partial output powers near the global optimal solution is determined by a flexible decomposed network strategy and then the final optimal solution is obtained by parallel Particle Swarm Optimization. The proposed approach tested on 6 generating units with smooth cost function, and to 26-bus (6 generating units) with consideration of prohibited zone effect, the simulation results compared with recent global optimization methods (Bee-OPF, GA, MTS, SA, PSO). From the different case studies, it is observed that the proposed approach provides qualitative solution with less computational time compared to various methods available in the literature survey.
\end{abstract}

Keywords: Parallel Genetic Algorithm, Decomposed Network, PSO, Economic dispatch, Optimal power flow, System security, Planning and control

\section{Introduction}

The main objective of an economic power dispatch strategy is to determine the optimal operating state of a power system by optimizing a particular objective while satisfying certain specified physical and operating constraints. In its most general formulation, the economic power dispatch (EPD) is a nonlinear, nonconvex, largescale, static optimization problem with both continuous and discrete control variables. It becomes even more complex when flexible ac transmission systems (FACTS) devices are taken into consideration as control variables [1]-[2].

The global optimization techniques known as genetic algorithms (GA), simulated annealing (SA), tabu search (TS), and evolutionary programming (EP), which are the forms of probabilistic heuristic algorithm have been successfully used to overcome the non-convexity problems of the constrained ED [3].

The literature on the application of the global optimization in the OPF problem is vast and [4] represents the major contributions in this area. In [5] authors present an enhanced genetic algorithm (EGA) for the solution of the OPF problem with both continuous and discrete control variables. The continuous control variables modelled are unit active power outputs and generator-bus voltage magnitudes, while the discrete ones are transformer-tap settings and shunt devices.

Authors in [6] present a Bee optimization algorithm (BeeOA), to solve the economic power dispatch (EPD)

$\dagger$ Corresponding Author: Dept. of Electrical Engineering, Biskra University, Algeria (bemahdad@yahoo.fr)

* Dept. of Electrical Engineering, Biskra University, Algeria (bemahdad@yahoo.fr)

* Laboratoire Brestois de Mécanique et des Systèmes, University of Brest, m.benbouzid@ieee.org)

Received : June 30, 2009; Accepted : December 17, 2009 with consideration of valve point effects, in [7] authors present a novel string structure for solving the economic dispatch through genetic algorithm (GA). To accelerate the search process authors in [8] proposed a multiple tabu search algorithm (MTS) to solve the dynamic economic dispatch (ED) problem with generator constraints, simulation results prove that this approach is able to reduce the computational time compared to the conventional approaches. Authors in [9] present an algorithm based simulated annealing to solve the optimal power flow.

PSO has parallel search techniques. Due to its high potential for global optimization, PSO has received great attention in solving optimal power flow (OPF) problems with consideration of discontinuous fuel cost functions. Author in [10] present a Particle swarm optimization to solving the economic dispatch considering the generator constraints.

In general to overcome the drawbacks of the conventional methods related to the form of the cost function, and to reduce the computational time related to the large space search required by GA, authors in [11] proposed an efficient decomposed GA for the solution of large-scale OPF with consideration of shunt FACTS devices under severe loading conditions. This paper presents an improved parallel PSO (IPPSO) for the solution of the economic dispatch with consideration of discontinues practical generation constraints. The length of the original particles is reduced successively based on the decomposition level and adapted with the topology of the new partitioned network. Partial decomposed active power demand added as a new dynamic variable and searched within the active power generation variables for the successive decomposed particles. Fig.1 shows the improved parallel swarm optimization (IPPSO) approach combined with FACTS devices to enhance the economic power dispatch (EPD). 


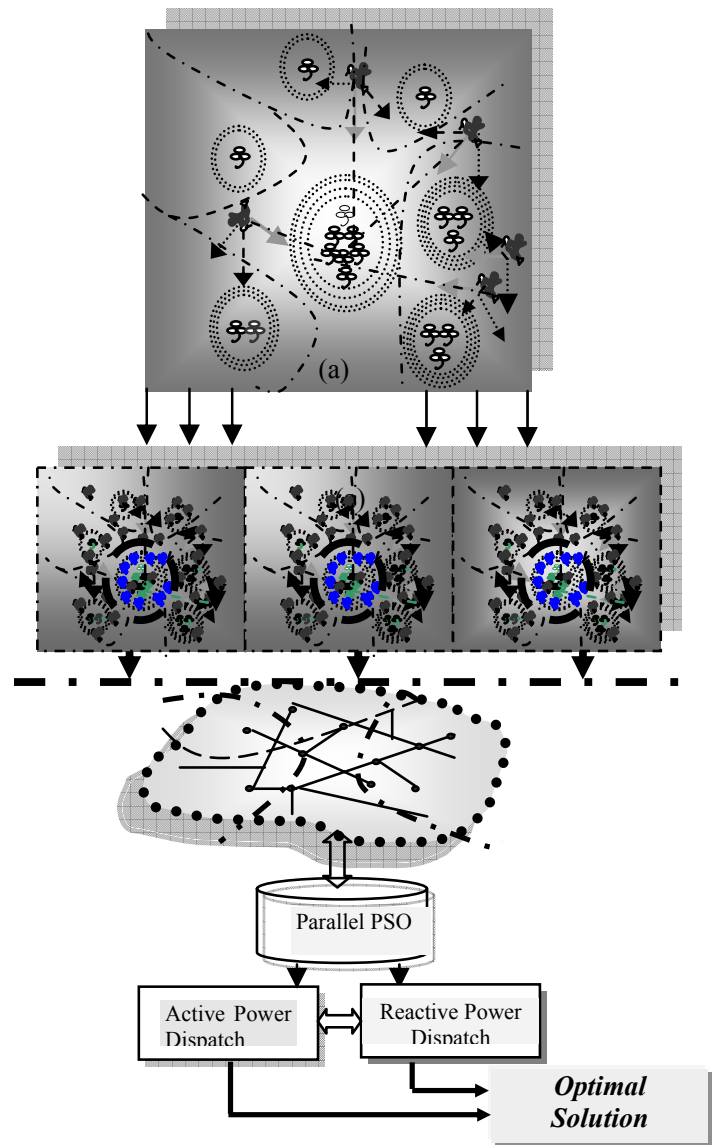

Fig. 1. Global search mechanism based decomposed network using improved parallel PSO.

\section{Active Power Dispatch Formulation with Discontinuous Fuel Cost Functions}

The main role for economic dispatch is to minimize the total generation cost of the power system but still satisfying specified constraints (generators constraints and security constraints). Fig. 2 shows the economic dispatch strategy.

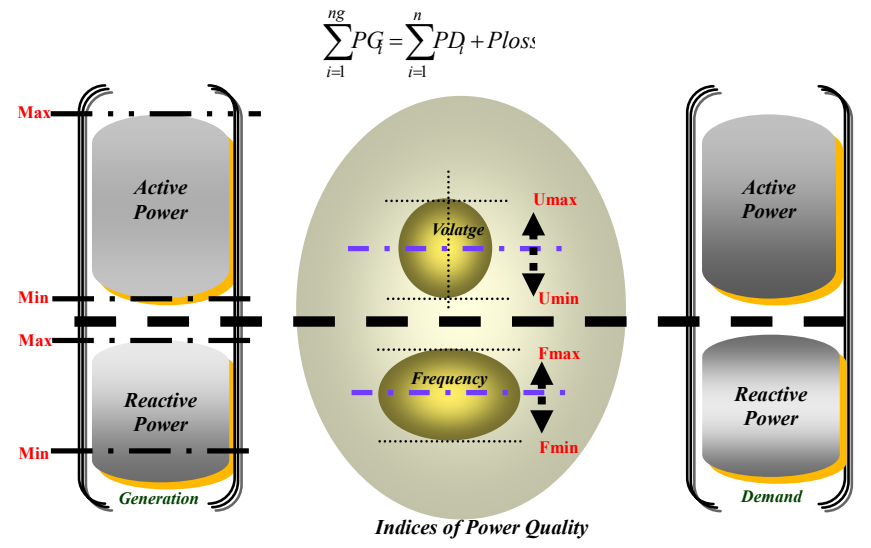

Fig. 2. Economic dispatch strategy.

For optimal active power dispatch, the simple objective function $f$ is the total generation cost as expressed follows:

$$
\text { Min } f=\sum_{i=1}^{N_{g}}\left(a_{i}+b_{i} P_{g i}+c_{i} P_{g i}^{2}\right)
$$

where $N_{g}$ is the number of thermal units, $P_{g i}$ is the active power generation at unit $\mathrm{i}$ and $a_{i}, b_{i}$ and $c_{i}$ are the cost coefficients of the $i^{t h}$ generator.

\subsection{The Equality Constraints}

In the power balance criterion, the equality constraint should be satisfied as the real and reactive power balance equations, expressed as follows:

$$
\sum_{i=1}^{N G} P_{g i}-P_{D}-P_{l o s s}=0
$$

where $N G$ represents the total number of generators, $P_{D}$ is the total active power demand, $P_{\text {loss }}$ represent the transmission losses, the $P_{\text {loss }}$ are calculated using power flow coefficients $B_{i j}$ by the following formula:

$$
P_{\text {loss }}=\sum_{i=1}^{N G N G} \sum_{j=1} P_{g i} B_{i j} P_{g j}+\sum_{i=1}^{N G} B_{0 i} P_{g i}+B_{00}
$$

\subsection{The inequality Constraints}

- Upper and lower limits on the active power generations:

$$
P_{g i}^{\min } \leq P_{g i} \leq P_{g i}^{\max }
$$

- Ramp-rate limits constraints:

$$
\begin{aligned}
& \max \left(P_{g i}^{\min }, P_{g i}(t-1)-D R_{i}\right) \leq P_{g i}(t) \\
& \leq \min \left(P_{g i}^{\max }, P_{g i}(t-1)+U R_{i}\right)
\end{aligned}
$$

- Prohibited operating zones constraints:

$$
P_{g i} \in\left\{\begin{array}{l}
P_{g i}^{\min } \leq P_{g i} \leq P_{g i, 1}^{1} \\
P_{g i, k-1}^{u} \leq P_{g i} \leq P_{g i, k}^{1}, \quad k=2, \ldots \ldots ., z_{i} \\
P_{g i, z_{i}}^{u} \leq P_{g i} \leq P_{g i}^{\max }
\end{array}\right.
$$

where $z_{i}$ is the number of prohibited zones of unit $\mathrm{i}$;

$P_{i}^{\min }$ and $P_{i}^{\max }$ are the minimum and maximum outputs of the ith generation unit;

$\mathrm{k}$ is the index of prohibited zones of a unit $\mathrm{i}$;

$P_{i, k}^{1 / u}$ is the lower/upper bounds of the $\mathrm{k}^{\text {th }}$ prohibited zone of unit $\mathrm{i}$; 


\section{Overview of PSO Technique}

The PSO can best be understood thought an analogy similar to the one that led to the development of the PSO. Imagine a swarm of bees in a field [12]. Their goal is to find in the field the location with the highest density of flowers without any knowledge of the field a priori, the bees begin in random locations with random velocities looking for flowers each bee can remember the locations that it found the most flowers, and somehow knows the locations where the others bees found an abundance of flowers. The main target is that the bees explore the field: overlying locations of greatest concentration hoping to find the absolute highest concentration of flowers. Soon, all the bees swarm around this point. Unable to find any points of higher flower concentration, they are continually drawn back to the highest flower concentration as indicated in Fig 3 (a, b). Fig. 4.
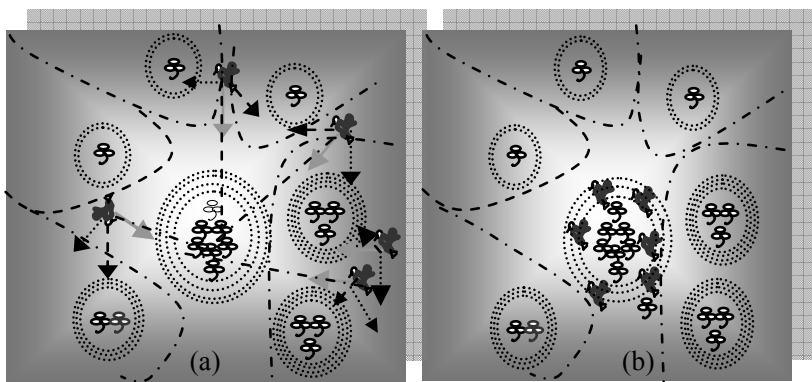

Fig. 3. (a) swarm mechanism search: The particles in PSO are attracted both to the area of highest concentration found by the entire swarm, and the best location personally encountered by the particle.

(b) All the bees swarm around the best location.

\subsection{Problem Formulation}

Let $X_{i}=\left(x_{i 1} \ldots \ldots x_{i n}\right)$, and $V_{i}=\left(v_{i 1} \ldots \ldots v_{i n}\right)$ denote the coordinates and the corresponding flight speed of the particle $i$ in a search space, respectively. The velocity of the particle is changed according to the relative locations of Pbest and Gbest. It is accelerated in the directions of these locations of greatest fitness according to the following equation [13]-[14].

$$
\begin{aligned}
V_{i}^{k+1}= & \omega V_{i}^{k}+c_{1} \text { rand } \times\left(\text { Pbest }_{i}^{k}-X_{i}^{k}\right) \\
& +c_{2} \text { Rand } \times\left(\text { Gbest }_{i}^{k}-X_{i}^{k}\right)
\end{aligned}
$$

where

$V_{i}^{k}$ velocity of particle i at iteration $\mathrm{k}$;

$\omega$ inertia weight factor;

$c_{1}, c_{2}$ acceleration constant;

$X_{i}^{k}$ position of particle i at iteration k;

Pbest $_{i}^{k}$ best position of particle i until iteration k;

Gbest $_{i}^{k}$ best position of group until iteration k;

Once the velocity has been determined it is simple to move the particle to its next location, and a new coordinate $X_{i}^{k+1}$ is computed for each of the $\mathrm{N}$ dimensions according the following equation:

$$
X_{i}^{k+1}=X_{i}^{k}+V_{i}^{k+1}
$$

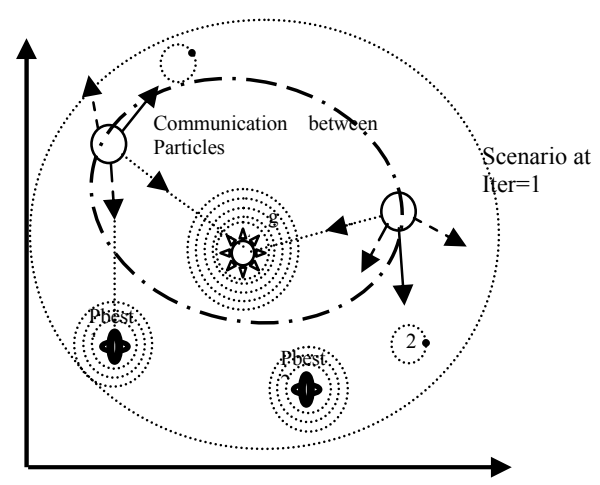

Fig. 4. The search mechanism of the particle swarm optimization.

\subsection{Algorithm Steps for Economic Dispatch based Swarm}

\section{(1) Chromosome Structure}

The active power generations of units are taken as the particles of the PSO. Fig. 5 shows the particles structure

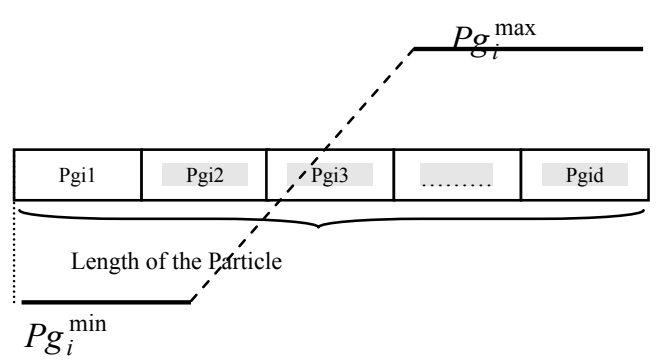

Fig. 5. Particles structure.

where $\mathrm{n}$ means population size, $\mathrm{d}$ is the number of generator, and $P g_{\text {id }}$ is the generation power output of the $\mathrm{d}^{\text {th }}$ unit at $\mathrm{i}^{\text {th }}$ individual.

\section{(2) Evaluation Function}

The structure of Evaluation function $f$ or fitness function is important to speed up the convergence of the iteration procedure. The evaluation function [10] is adopted as (9). It is the reciprocal of the generation cost function $F_{\text {cost }}\left(P g_{i}\right)$ and power balance constraint $F_{p b c}\left(P g_{i}\right)$ as in (2).

$$
f=\frac{1}{F_{\cos t}+F_{p b c}}
$$

where 


$$
\begin{gathered}
F_{\text {cos } t}=1+a b s \frac{\left(\sum_{i=1}^{n} F_{i}\left(P g_{i}\right)-F_{\min }\right)}{\left(F_{\max }-F_{\min }\right)} \\
F_{p b c}=1+\left(\sum_{i=1}^{n} P g_{i}-P_{D}-P_{\text {loss }}\right)^{2}
\end{gathered}
$$

$F_{\max }$ maximum generation cost among all individuals in the initial population;

$F_{\text {min }}$ minimum generation cost among all individuals in the initial population.

\subsection{Calculation Steps of the Proposed Method}

The PSO algorithm is as follows:

Step1: the particles are randomly generated between the maximum and minimum operating limits of units.

Step2: The particle velocities are generated randomly.

Step3: Objective function values of the particles are evaluated. These values are set the best value of the particles.

Step4: the best value among all the pbest values (gbest) is identified.

Step5: new velocities for the particles are calculated using (7). The new velocity is simply the old velocity scaled by $\omega$ and increased in the direction of gbest and pbest for that particle dimension. $c_{1}$ and $c_{2}$ are scaling factors that determine the relative 'pull' of pbest and gbest. $c_{1}$ is a factor determining how much the particle is influenced by the memory of his best location, and $c_{2}$ is a factor determining how much the particle is influenced by the rest of the Swarm [15].

In this paper, the weighting factor is defined as follows.

$$
\omega=\omega_{\max }-\frac{\omega_{\max }-\omega_{\min }}{\text { Iter }_{\max }} \times \text { Iter }
$$

where

$$
\begin{array}{ll}
\omega_{\max }, \omega_{\min } & : \text { initial, final weights; } \\
\text { Iter }_{\max } & : \text { maximum iteration number; } \\
\text { Iter } & \text { :current iteration number. }
\end{array}
$$

Step6: the positions for each particle are updated using (8).

The resulting position of a particle is not always guaranteed to satisfy the inequality constraints.

$$
\text { If } v_{i, j}>V_{j}^{\max } \text {, then } v_{i, j}=V_{j}^{\max } \text {. If } v_{i, j}<V_{j}^{\min } \text {, then } v_{i, j}=V_{j}^{\min }
$$

Stap7: New objective function values are calculated for the new positions of the particles. If the new value is better than the previous pbest, the new value is set to pbest. If the stopping criterion is met, the positions of particles represent the optimal solution; otherwise the procedure is repeated from step4.

\section{Strategy of the Proposed Approach}

\subsection{Initialization based in Decomposition Procedure}

The main idea of the proposed approach is to optimize the active power demand for each partitioned network to minimize the total fuel cost. An initial candidate solution generated for the global $\mathrm{N}$ population size.

- For each decomposition level estimate the initial active power demand:

$$
\begin{gathered}
\text { For } \mathrm{NP}=2 \quad \text { Do } \\
P d 1=\sum_{i=1}^{M 1} P_{G i} \\
P d 2=\sum_{i=1}^{M 2} P_{G i}=P D-P d 1
\end{gathered}
$$

Where NP the number of partition

$P d 1$ : the active power demand for the first initial partition.

$P d 2$ : the active power demand for the second initial partition.

$P D$ : the total active power demand for the original network.

The following equilibrium equation should be verified for each decomposed level:

For level 1:

$$
P d 1+P d 2=P D+\text { Ploss }
$$

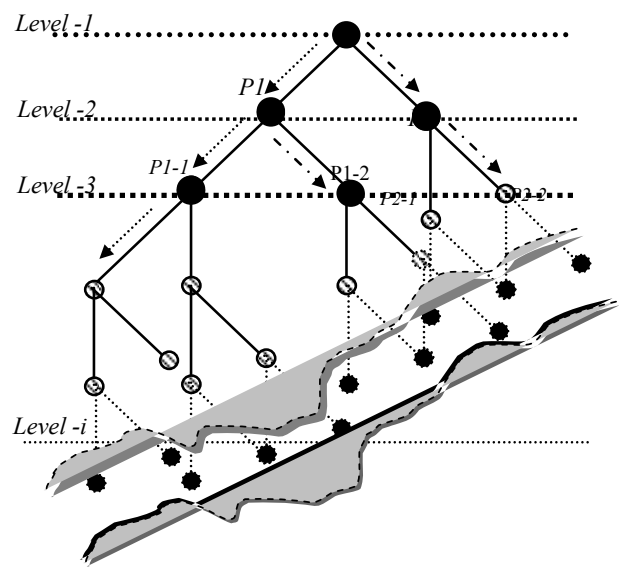

Fig. 6. Sample of network with tree decomposition.

- Fitness Evaluation based Load Flow

For all sub-systems generated perform a load flow calculation to evaluate the proposed fitness function. A candidate solution formed by all sub-systems is better if its fitness is higher.

$$
\begin{gathered}
f_{i}=1 /\left(F_{\cos t}+\omega_{l} F_{l i}+\omega_{V} F_{V i}\right) \\
F_{V i}=\sum_{j=1}^{N P Q}\left(V_{P Q i j}-V_{P Q i j}^{\lim } \mid\right) /\left(V_{P Q i j}^{\max }-V_{P Q i j}^{\min } \mid\right)
\end{gathered}
$$


where $f_{i}$ is fitness function for sub-systems decomposed at level $\mathrm{i}$.

$F_{l i}$ denotes the per unit power loss generated by subsystems at level i; $F_{\cos t}$ denotes the total cost of the active power planning related to the decomposition level i; $F_{V i}$ denotes the sum of the normalized violations of voltages related to the sub-systems at level i.

- Consequently under this concept, the final value of active power demand should satisfy the following equations.

$$
\begin{gathered}
\sum_{i=1}^{N_{g}}\left(P g_{i}\right)=\sum_{i=1}^{\text {part }_{i}}\left(P d_{i}\right)+\text { ploss } \\
P g_{i}^{\min } \leq P g_{i} \leq P g_{i}^{\max }
\end{gathered}
$$

\subsection{Final Search Mechanism}

- All the sub-systems are collected to form the original network, global data base generated based on the best results $U_{\text {best }}^{\text {Part }}$ of partition ' $i$ ' found from all sub-populations.

- The final solution $U_{\text {best }}^{\text {Global }}$ is found out after reactive power planning procedure to adjust the reactive power generation limits, and voltage deviation, the final optimal cost is modified to compensate the reactive constraints violations. Fig. 6 shows an example of tree network decomposition used to search the global database. Fig. 7 illustrates the basic steps of the proposed approach.

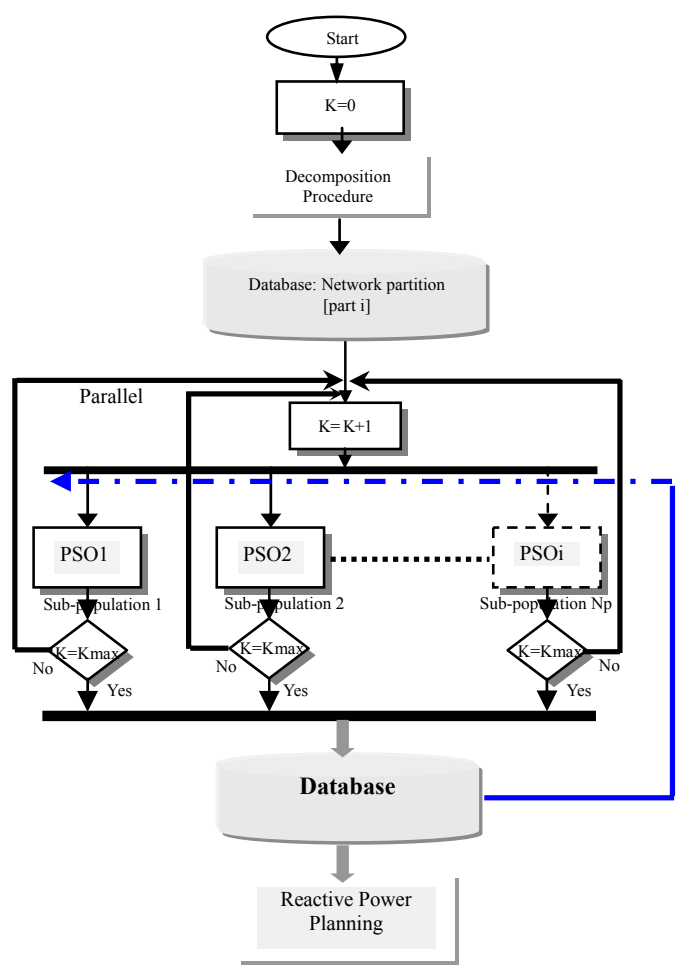

Fig. 7. Procedure of parallel swarm optimization approach for EPD.

\section{Application Study}

The proposed algorithm is developed in the Matlab programming language using 6.5 version. The proposed approach has been tested on two test network ( 6 generating units without prohibited zones, and 6 generating units with prohibited zones).

i) IPPSO Parameters

- population size $=50-100$

- generations=50-100

- inertia weight factor $\mathrm{w}$ is set by (12), where $\omega_{\max }=0.9$ and $\omega_{\min }=0.4$

- acceleration constant $\mathrm{c} 1=1.85$ and $\mathrm{c} 2=2.1$.

\subsection{Test System 1}

The first test system has 6 generating units; the characteristics of the six units are given in Table 1. The load demands are 800, 1200 and 1800 MW. In this example the power losses, the ramp rate limits and prohibited zones of the units are not taken into account.

Figs. 8-9-10 show the convergence of the proposed approach for the three partitioned subsystems. The best cost for each partition network obtained with minimum iteration less than 30 iterations. Tables 2-3-4 show the results of the minimum cost obtained by different methods at different loading conditions. The total costs at different loading conditions obtained with the proposed approach are better than the results found from the methods cited in the literature.

Table 1. Technical admissible parameters of generators and the fuel cost Coefficients

\begin{tabular}{c|c|c|c|c|c}
\hline $\begin{array}{c}\text { Bus } \\
\text { Number }\end{array}$ & $\begin{array}{c}\text { Pmin } \\
{[M W]}\end{array}$ & $\begin{array}{c}\text { Pmax } \\
{[M W]}\end{array}$ & $\begin{array}{c}a \\
{[\$ / h r]}\end{array}$ & $\begin{array}{c}b \\
{[\$ / M W h r]}\end{array}$ & $\begin{array}{c}c \\
{\left[\$ / M W^{2} h r\right]}\end{array}$ \\
\hline 1 & 100 & 600 & 561 & 7.92 & 0.001562 \\
\hline 2 & 100 & 400 & 310 & 7.85 & 0.001940 \\
\hline 3 & 50 & 200 & 78 & 7.97 & 0.004820 \\
\hline 4 & 140 & 590 & 500 & 7.06 & 00.00139 \\
\hline 5 & 110 & 440 & 295 & 7.46 & 00.00184 \\
\hline 6 & 110 & 440 & 295 & 7.46 & 00.00184 \\
\hline
\end{tabular}

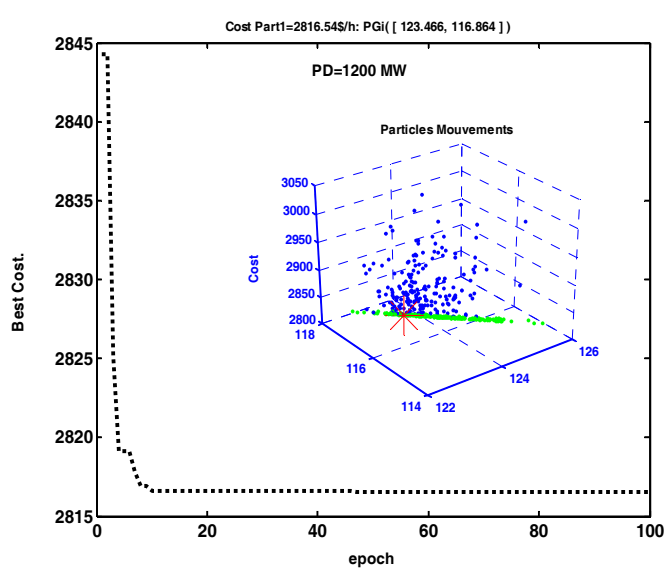

Fig. 8. Convergence of the proposed approach for the first partition: $\mathrm{PD}=1200 \mathrm{MW}$. 


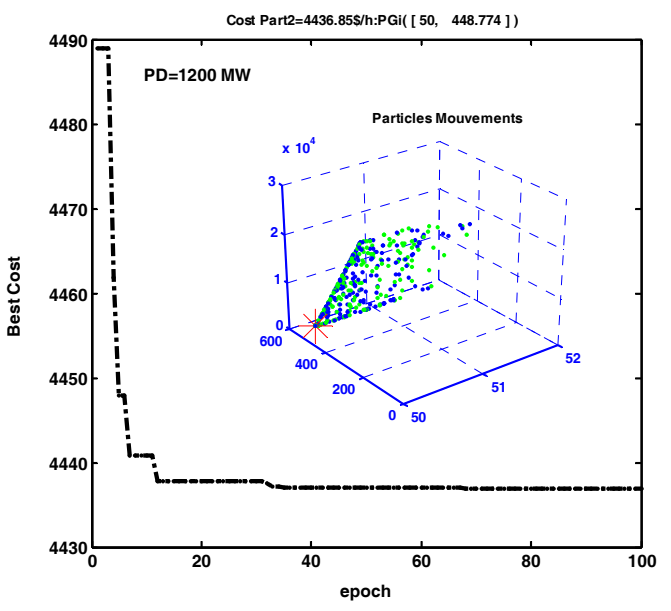

Fig. 9. Convergence of the proposed approach for the second partition: $\mathrm{PD}=1200 \mathrm{MW}$.

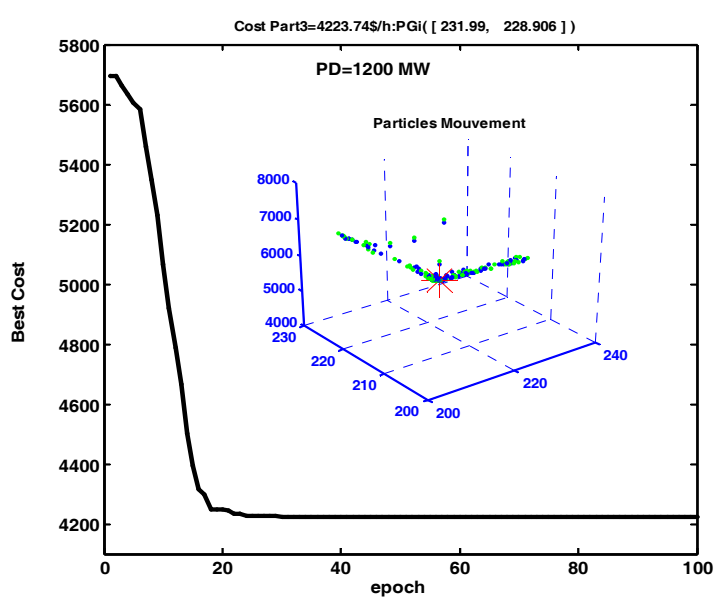

Fig. 10. Convergence of the proposed approach for the third partition: $\mathrm{PD}=1200 \mathrm{MW}$.

Table 2. Minimum generation cost obtained by different methods on 6-generating units systems: $\mathrm{PD}=800 \mathrm{MW}$

\begin{tabular}{c|c|c|c|c}
\hline Units & $C G A[6]$ & $Q E G A[6]$ & BeeOA $[6]$ & Our Approach \\
\hline$P_{g 1}$ & 109.17 & 104.89 & 100.00 & $\mathbf{1 0 0 . 0 0}$ \\
\hline$P_{g 2}$ & 104.08 & 105.87 & 100.00 & $\mathbf{1 0 0 . 0 0}$ \\
\hline$P_{g 3}$ & 52.04 & 51.74 & 50.00 & $\mathbf{5 0 . 0 0}$ \\
\hline$P_{g 4}$ & 305.05 & 314.18 & 305.63 & $\mathbf{3 0 5 . 6 2 0 1}$ \\
\hline$P_{g 5}$ & 114.83 & 113.16 & 122.19 & $\mathbf{1 1 9 . 7 3 2 6}$ \\
\hline$P_{g 6}$ & 114.83 & 113.16 & 122.19 & $\mathbf{1 2 4 . 6 4 7 1}$ \\
\hline Load $(\mathrm{MW})$ & $\mathbf{8 0 0}$ & $\mathbf{8 0 0}$ & $\mathbf{8 0 0}$ & $\mathbf{8 0 0}$ \\
\hline Total Cost $(\$ / h)$ & 8232.89 & 8231.03 & 8227.10 & $\mathbf{8 2 2 7 . 1 0}$ \\
\hline
\end{tabular}

Table 3. Minimum generation cost obtained by different methods on 6-generating units systems: $\mathrm{PD}=1200 \mathrm{MW}$

\begin{tabular}{c|r|r|r|r}
\hline Units & CGA [6] & QEGA [6] & BeeOA [6] & Our Approach \\
\hline$P_{g 1}$ & 142.55 & 131.50 & 123.76 & $\mathbf{1 2 0 . 2 9 6 8}$ \\
\hline$P_{g 2}$ & 117.80 & 129.05 & 117.68 & $\mathbf{1 2 0 . 0 3 2 5}$ \\
\hline$P_{g 3}$ & 58.90 & 52.08 & 50.00 & $\mathbf{5 1 . 0 6 0 7}$ \\
\hline$P_{g 4}$ & 515.20 & 494.08 & 448.42 & $\mathbf{4 4 7 . 7 1 3 9}$ \\
\hline$P_{g 5}$ & 182.78 & 200.61 & 230.06 & $\mathbf{2 3 1 . 8 1 2 9}$ \\
\hline$P_{g 6}$ & 182.78 & 200.61 & 230.06 & $\mathbf{2 2 9 . 0 8 3 5}$ \\
\hline Load $(\mathrm{MW})$ & $\mathbf{1 2 0 0}$ & $\mathbf{1 2 0 0}$ & $\mathbf{1 2 0 0}$ & $\mathbf{1 2 0 0}$ \\
\hline Total Cost $(\$ / h)$ & 11493.74 & 11480.03 & 11477.08 & $\mathbf{1 1 4 7 7 . 0 0}$ \\
\hline
\end{tabular}

Table 4. Minimum generation cost obtained by different methods on 6-generating units systems: $\mathrm{PD}=1800 \mathrm{MW}$

\begin{tabular}{c|r|r|r|r}
\hline Units & CGA [6] & QEGA [6] & BeeOA [6] & Our Approach \\
\hline$P_{g 1}$ & 222.42 & 250.49 & 247.99 & 249.2971 \\
\hline$P_{g 2}$ & 190.73 & 215.43 & 217.719 & 216.4120 \\
\hline$P_{g 3}$ & 95.36 & 109.92 & 75.18 & 74.2414 \\
\hline$P_{g 4}$ & 555.63 & 572.84 & 588.04 & 589.0095 \\
\hline$P_{g 5}$ & 367.92 & 325.66 & 335.52 & 338.1559 \\
\hline$P_{g 6}$ & 367.92 & 335.52 & 335.53 & 332.8841 \\
\hline Load $(\mathrm{MW})$ & $\mathbf{1 8 0 0}$ & $\mathbf{1 8 0 0}$ & $\mathbf{1 8 0 0}$ & $\mathbf{1 8 0 0}$ \\
\hline Total Cost $(\$ / h)$ & 16589.05 & 16585.85 & 16579.33 & $\mathbf{1 6 5 7 9 . 0 0}$ \\
\hline
\end{tabular}

\subsection{Test System 2}

This case study consisted of six generation units, 26 buses and 46 transmission lines. All thermal units are within the ramp rate limits and prohibited zones. The characteristics of the six units are given in Table 5 and 6. All data of this test system can be retrieved from [10]. In this case, the load demand expected to be determined was $\mathrm{PD}=1263 \mathrm{MW}$. The B matrix of the transmission loss coefficient is given by:

$$
\begin{aligned}
& B_{i j}=10^{-3}\left[\begin{array}{cccccc}
1.7 & 1.2 & 0.7 & -0.1 & -0.5 & -0.2 \\
1.2 & 1.4 & 0.9 & 0.1 & -0.6 & -0.1 \\
0.7 & 0.9 & 3.1 & 0.0 & -1.0 & -0.6 \\
-0.1 & 0.1 & 0.0 & 0.24 & -0.6 & -0.8 \\
-0.5 & -0.6 & -0.6 & -0.6 & 12.9 & -0.2 \\
-0.2 & -0.1 & -0.6 & -0.8 & -0.2 & 15.0
\end{array}\right] \\
& B_{i 0}=10^{-3} \cdot\left[\begin{array}{llllll}
-0.3908 & -0.1297 & -0.7047 & -0.0591 & 0.2161 & -0.6635
\end{array}\right] \\
& B_{00}=0.056
\end{aligned}
$$

Table 5. Generating units capacity and cost coefficients: 26-bus test system

\begin{tabular}{c|c|c|c|c|c}
\hline $\begin{array}{c}\text { Bus } \\
\text { Number }\end{array}$ & $\begin{array}{c}\text { Pmin } \\
{[M W]}\end{array}$ & $\begin{array}{c}\text { Pmax } \\
{[M W]}\end{array}$ & $\begin{array}{c}a \\
{[\$ / h r]}\end{array}$ & $\begin{array}{c}b \\
{[\$ / M W h r]}\end{array}$ & $\begin{array}{c}c \\
{\left[\$ / M W^{2} h r\right]}\end{array}$ \\
\hline 1 & 100 & 500 & 240 & 7.0 & 0.0070 \\
\hline 2 & 50 & 200 & 200 & 10.0 & 0.0095 \\
\hline 3 & 80 & 300 & 220 & 8.5 & 0.0090 \\
\hline 4 & 50 & 150 & 200 & 11.0 & 0.0090 \\
\hline 5 & 50 & 200 & 220 & 10.5 & 0.0080 \\
\hline 6 & 50 & 120 & 190 & 12.0 & 0.0075 \\
\hline
\end{tabular}

\begin{tabular}{|c|c|c|c|c|}
\hline $\begin{array}{c}\text { Bus } \\
\text { Number }\end{array}$ & $P_{i}^{O}$ & $\begin{array}{c}U R i \\
{[M W / h]}\end{array}$ & $\begin{array}{c}D R i \\
{[\$ / h r]}\end{array}$ & $\begin{array}{c}\text { Prohibited zones } \\
{[M W]}\end{array}$ \\
\hline 1 & 440 & 80 & 120 & {$\left[\begin{array}{lll}210 & 240\end{array}\left[\begin{array}{lll}350 & 380\end{array}\right]\right.$} \\
\hline 2 & 170 & 50 & 90 & {$\left[\begin{array}{ll}90 & 110\end{array}\right]\left[\begin{array}{lll}140 & 160\end{array}\right]$} \\
\hline 3 & 200 & 65 & 100 & {$\left[\begin{array}{lll}150 & 170\end{array}\left[\begin{array}{lll}210 & 240\end{array}\right]\right.$} \\
\hline 4 & 150 & 50 & 90 & {$\left[\begin{array}{ll}80 & 90\end{array}\right]\left[\begin{array}{ll}110 & 120\end{array}\right]$} \\
\hline 5 & 190 & 50 & 90 & {$\left[\begin{array}{ll}90 & 110\end{array}\right]\left[\begin{array}{lll}140 & 150\end{array}\right]$} \\
\hline 6 & 110 & 50 & 90 & {$\left[\begin{array}{lll}75 & 85\end{array}\right]\left[\begin{array}{lll}100 & 105\end{array}\right]$} \\
\hline
\end{tabular}

Table 6. Ramp Rate limits and prohibited zones of generating units: 26-bus test system

Table 7 shows the performance comparison among the proposed algorithms, a particle swarm optimization (PSO) approach [10], a novel string based GA [7], standard ge- 
netic algorithm (GA) method [10], multiple tabu search algorithm (MTS) [8], and the simulated annealing (SA) method [9]. The simulation results of the proposed approach outperformed recent optimization methods presented in the literature in terms of solution quality and time convergence.

Table 7. Results of the minimum cost and power generation compared with global optimization methods for 26-Bus test system

\begin{tabular}{|c|c|c|c|c|c|c|c|}
\hline \multicolumn{2}{|c|}{$\begin{array}{l}\text { Generators } \\
\text { (MW) }\end{array}$} & \multirow{2}{*}{$\begin{array}{c}\mathrm{SA}[9] \\
478.1258\end{array}$} & \multirow{2}{*}{\begin{tabular}{|c|}
$\begin{array}{c}\text { New-string } \\
\text { GA [7] }\end{array}$ \\
446.7100 \\
\end{tabular}} & \multirow{2}{*}{$\begin{array}{l}\text { GA [8] } \\
474.8066 \\
\end{array}$} & \multirow{2}{*}{$\begin{array}{c}\text { MTS[8] } \\
448.1277 \\
\end{array}$} & \multirow{2}{*}{$\begin{array}{c}\mathrm{PSO}[10] \\
447.4970\end{array}$} & \multirow{2}{*}{$\begin{array}{l}\begin{array}{c}\text { Our Ap- } \\
\text { proach }\end{array} \\
447.8293 \\
\end{array}$} \\
\hline$P P_{g I}$ & & & & & & & \\
\hline$P_{g 2}$ & & 163.0249 & \begin{tabular}{|l|}
173.0100 \\
\end{tabular} & 178.6363 & 172.8082 & 173.3221 & 172.1145 \\
\hline$P_{g 3}$ & \multirow{2}{*}{ Part2 } & & & & & & \\
\hline$P_{g 4}$ & & & & & & & \\
\hline$P_{g 5}$ & \multirow{2}{*}{ Part3 } & 153. & & & & & \\
\hline$P_{g 6}$ & & & & & & & \\
\hline \multicolumn{2}{|c|}{ Total PG } & & & & & & \\
\hline \multicolumn{2}{|c|}{ Ploss (MW) } & & & & & & \\
\hline \multicolumn{2}{|c|}{$\operatorname{Cost}[\$ / \mathrm{hr}]$} & 1.10 & 47.00 & .00 & 50.06 & & 37.00 \\
\hline \multicolumn{2}{|c|}{ CPU time(s) } & & 8.36 & & 1.29 & 14.89 & 1.4120 \\
\hline
\end{tabular}

The performance of the convergence characteristics for the three partitioned network are shown clearly in Figs. 11, 12,13 . The computational time of the proposed approach is reduced significantly in comparison to the other methods.

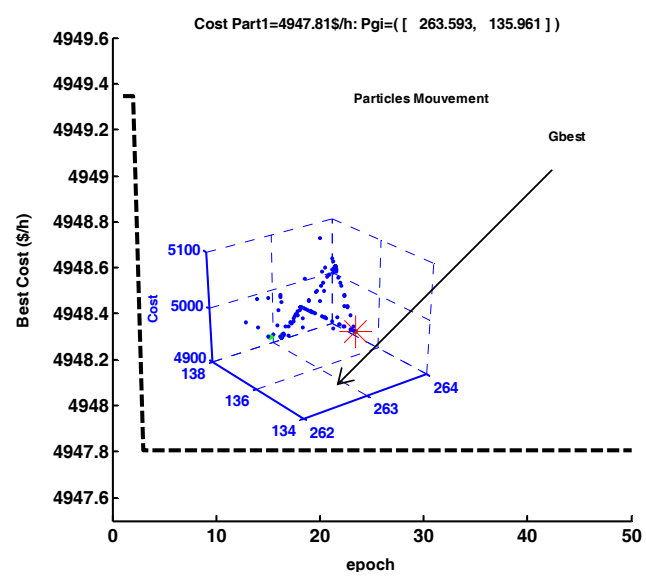

Fig. 11. Convergence of the proposed approach for the first partition: $\mathrm{PD}=1263 \mathrm{MW}$.

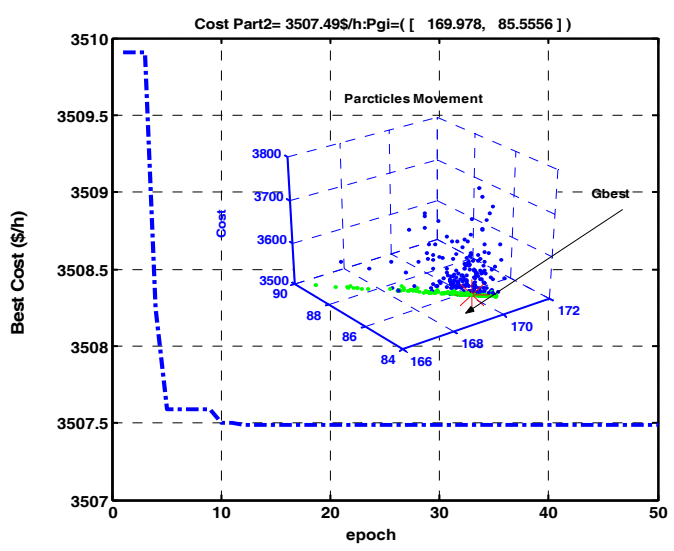

Fig. 12. Convergence of the proposed approach for the second partition: $\mathrm{PD}=1263 \mathrm{MW}$.

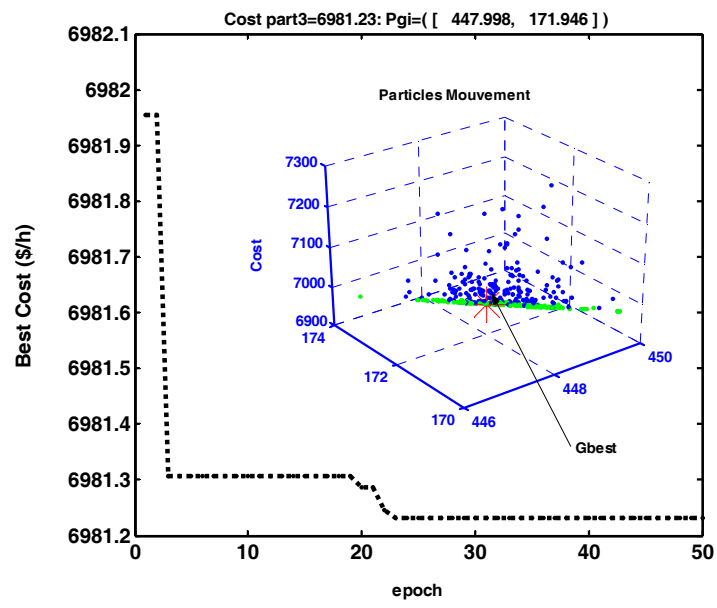

Fig. 13. Convergence of the proposed approach for the third partition: $\mathrm{PD}=1263 \mathrm{MW}$.

\section{Discussions}

\subsection{Robustness Test}

The performance of the proposed approach must be concluded after many trials with different initializations. Table 8,9 , and Table 10 show the best cost solution for 8 trials. From the sample results it is evident that the proposed approach is more consistent.

\subsection{Computational Efficiency}

Computational efficiency analysis is an important index to test and validate the robustness of an algorithm. The mean CPU time to converge to the best solution have been observed and shown in Table 7. For the proposed approach the IPPSO takes an average CPU time of $1.412 \mathrm{~s}$ to find the best solution of the second test system. This time is given after identification of the global data base containing the best partitioned network.

Table 8. EP-PSO for 6-generating units: results and convergence characteristics: $\mathrm{PD}=800 \mathrm{MW}$

\begin{tabular}{|c|c|c|c|c|c|}
\hline \multicolumn{6}{|c|}{ Real Power Output and Cost $P_{G}[\mathrm{MW}], \mathbf{P D}=\mathbf{8 0 0} \mathbf{~ M W}$} \\
\hline \multicolumn{2}{|c|}{ Bus N $^{\circ}$} & Run1 & Run2 & Run3 & Run4 \\
\hline 1 & \multirow{2}{*}{ Part1 } & 100.0000 & 100.0000 & 100.0000 & 100.0000 \\
\hline 2 & & 100.0000 & 100.0000 & 100.0000 & 100.0000 \\
\hline 3 & \multirow{2}{*}{ Part2 } & 50.0000 & 50.0000 & 50.0000 & 50.0000 \\
\hline 4 & & 305.6201 & 305.6201 & 305.6201 & 305.6201 \\
\hline 5 & \multirow{2}{*}{ Part3 } & 120.0626 & 122.0641 & 119.7326 & 119.3084 \\
\hline 6 & & 124.3173 & 122.3158 & 124.6471 & 125.0716 \\
\hline \multicolumn{2}{|c|}{$\operatorname{Cost}[\$ / \mathrm{h}]$} & $\mathbf{8 2 2 7 . 1 0}$ & 8227.10 & 8227.10 & 8227.10 \\
\hline \multicolumn{2}{|c|}{ Ploss (MW) } & 0 & 0 & 0 & 0 \\
\hline \multicolumn{6}{|c|}{ Real Power Output and Cost } \\
\hline \multicolumn{2}{|c|}{ Bus N $^{\circ}$} & Run5 & Run6 & Run 7 & Run 8 \\
\hline 1 & \multirow{2}{*}{ Part1 } & 100.0000 & 100.0000 & 100.0000 & 100.0000 \\
\hline 2 & & 100.0000 & 100.0000 & 100.0000 & 100.0000 \\
\hline 3 & \multirow{2}{*}{ Part2 } & 50.0000 & 50.0000 & 50.0000 & 50.0000 \\
\hline 4 & & 305.6201 & 305.6201 & 305.6201 & 305.6201 \\
\hline 5 & \multirow{2}{*}{ Part3 } & 121.9559 & 121.6291 & 124.2006 & 123.5904 \\
\hline 6 & & 122.4240 & 122.7509 & 120.1792 & 120.7893 \\
\hline \multicolumn{2}{|c|}{$\operatorname{Cost}[\$ / h]$} & 8227.10 & 8227.10 & 8227.10 & 8227.10 \\
\hline \multicolumn{2}{|c|}{ Ploss (MW) } & 0 & 0 & 0 & 0 \\
\hline
\end{tabular}


Table 9. EP-PSO for 6-generating units: results and convergence characteristics: $\mathrm{PD}=1200 \mathrm{MW}$

\begin{tabular}{|c|c|c|c|c|c|}
\hline \multicolumn{6}{|c|}{ Real Power Output and Cost $P_{G}[\mathrm{MW}], \mathrm{PD}=1200 \mathrm{MW}$} \\
\hline \multicolumn{2}{|c|}{ Bus N $^{\circ}$} & Run1 & Run2 & Run3 & Run4 \\
\hline 1 & \multirow{2}{*}{ Part1 } & 122.9447 & 122.8026 & 120.2968 & 121.2401 \\
\hline 2 & & 117.3847 & 117.5268 & 120.0325 & 119.0893 \\
\hline 3 & \multirow{2}{*}{ Part2 } & 50.7519 & 50.0000 & 51.0607 & 50.6598 \\
\hline 4 & & 448.0230 & 448.7748 & 447.7139 & 448.1150 \\
\hline 5 & \multirow{2}{*}{ Part3 } & 232.0000 & 231.2201 & 231.8129 & 230.8963 \\
\hline 6 & & 228.8960 & 229.6764 & 229.0835 & 230.0000 \\
\hline \multicolumn{2}{|c|}{$\operatorname{Cost}[\$ / h]$} & 11477.00 & 11477.00 & 11477.00 & 11477.00 \\
\hline \multicolumn{2}{|c|}{ Ploss (MW) } & 0 & 0 & 0 & 0 \\
\hline \multicolumn{6}{|c|}{ Real Power Output and Cost } \\
\hline \multicolumn{2}{|c|}{ Bus N $^{\circ}$} & Run5 & Run6 & Run 7 & Run 8 \\
\hline 1 & \multirow{2}{*}{ Part1 } & 123.0859 & 123.0531 & 125.0111 & 123.4744 \\
\hline 2 & & 17.2435 & 117.2763 & 115.3184 & 116.8549 \\
\hline 3 & \multirow{2}{*}{ Part2 } & 50.0000 & 51.2571 & 50.6899 & 51.2558 \\
\hline 4 & & 448.7746 & 447.5175 & 448.0850 & 447.5169 \\
\hline 5 & \multirow{2}{*}{ Part3 } & 231.9073 & 232.0000 & 230.8965 & 232.0000 \\
\hline 6 & & 228.9887 & 228.8967 & 230.0000 & 228.8964 \\
\hline \multicolumn{2}{|c|}{$\operatorname{Cost}[\$ / h]$} & 11477.00 & 11477.00 & 11477.00 & 11477.00 \\
\hline \multicolumn{2}{|c|}{ Ploss (MW) } & 0 & 0 & 0 & 0 \\
\hline
\end{tabular}

Table 10. EP-PSO for six generating units: results and convergence characteristics: $\mathrm{PD}=1800 \mathrm{MW}$

\begin{tabular}{|c|c|c|c|c|c|}
\hline \multicolumn{6}{|c|}{ Real Power Output and Cost $P_{G}[\mathrm{MW}], \mathrm{PD}=1800 \mathrm{MW}$} \\
\hline \multicolumn{2}{|c|}{ Bus N $^{\circ}$} & Run1 & Run2 & Run3 & Run4 \\
\hline 1 & \multirow{2}{*}{ Part1 } & 248.2584 & 247.7467 & 247.8030 & 248.3835 \\
\hline 2 & & 217.4504 & 217.9623 & 217.9060 & 217.3256 \\
\hline 3 & \multirow{2}{*}{ Part2 } & 76.0276 & 76.7588 & 72.5827 & 75.0705 \\
\hline 4 & & 587.2233 & 586.4921 & 590.6682 & 588.1805 \\
\hline 5 & \multirow{2}{*}{ Part3 } & 333.3616 & 338.6819 & 337.5439 & 335.5557 \\
\hline 6 & & 337.6785 & 332.3580 & 333.4960 & 335.4843 \\
\hline \multicolumn{2}{|c|}{$\operatorname{Cost}[\$ / h]$} & 16579.00 & 16579.00 & 16579.00 & 16579.00 \\
\hline \multicolumn{2}{|c|}{ Ploss (MW) } & 0 & 0 & 0 & 0 \\
\hline \multicolumn{6}{|c|}{ Real Power Output and Cost } \\
\hline \multicolumn{2}{|c|}{ Bus N $^{\circ}$} & Run5 & Run6 & Run 7 & Run 8 \\
\hline 1 & \multirow{2}{*}{ Part1 } & 245.2436 & 248.7239 & 246.2992 & 249.2971 \\
\hline 2 & & 220.4653 & 216.9850 & 219.4099 & 216.4120 \\
\hline 3 & \multirow{2}{*}{ Part2 } & 75.8609 & 75.2985 & 75.4824 & 74.2414 \\
\hline 4 & & 587.3900 & 587.9524 & 587.7686 & 589.0095 \\
\hline 5 & \multirow{2}{*}{ Part3 } & 333.5527 & 335.9037 & 335.9272 & 338.1559 \\
\hline 6 & & 337.4873 & 335.1363 & 335.1127 & 332.8841 \\
\hline \multicolumn{2}{|c|}{$\operatorname{Cost}[\$ / h]$} & 16579.00 & 16579.00 & 16579.00 & 16579.00 \\
\hline \multicolumn{2}{|c|}{ Ploss (MW) } & 0 & 0 & 0 & 0 \\
\hline
\end{tabular}

\section{Conclusion}

Application of an improved parallel PSO to enhance the OPF solution with consideration of practical generation constraints is demonstrated in this paper. In the first stage a decomposition mechanism is proposed to search the efficient partitioned network. A global database generated containing the best technical sub-systems. In the second stage a parallel execution of the adapted PSO associated to each decomposed swarm.

The performance of the proposed approach was tested with 6 generating units with smooth cost function, and with another test system ( 26 bus test system) with consideration of valve point effect, the results of the proposed algorithm compared with recent global optimization method. It is observed that the proposed approach is capable of finding the near global solutions of non-linear and nondifferentiable objective functions and obtain a competitive solution at a reduced time.

\section{References}

[1] O. Alsac and B. stott. "Optimal load flow with steady state security," IEEE Trans. Power Appara. Syst., pp.745-751, May-June 1974.

[2] M. Huneault, and F. D. Galiana, "A survey of the optimal power flow literature," IEEE Trans. Power Systems, Vol.6, No.2, pp.762-770, May 1991.

[3] B. Mahdad, T. Bouktir, K. Srairi, "OPF with Environmental Constraints with SVC Controller using Decomposed Parallel GA: Application to the Algerian Network" Journal of Electrical Engineering \& Technology, Korea, Vol.4, No.1, pp.55-65, March 2009.

[4] R. C. Bansal, "Otimization methods for electric power systems: an overview," International Journal of Emerging Electric Power Systems, Vol.2, No.1, pp.1-23, 2005.

[5] A. G. Bakistzis, P. N. Biskas, C. E. Zoumas, and V. Petridis, "Optimal power flow by enhanced genetic algorithm, "IEEE Trans. Power Systems, Vol.17, No.2, pp.229-236, May 2002.

[6] R. Kumar, D. Sharma, and A. Kumar, "Economic power dispatch with valave point effects using Bee optimization algorithm" Journal of Electrical Engineering \& Technology, Korea, Vol.4, No.1, pp.19-27, March 2009.

[7] C. Chien Kuo, "A novel string structure for economic dispatch problems with practical constraints," Journal of Energy Conversion and management, Elsevier, Vol.49, pp.3571-3577, 2008.

[8] S. Pothiya, I. Nagamroo, and W. Kongprawechnon, "Application of mulyiple tabu search algorithm to solve dynamic economic dispatch considering generator constraints," Journal of Energy Conversion and management, Elsevier, Vol.49, pp.506-516, 2008.

[9] C. A. Roa-Sepulveda, B. J. Pavez-Lazo, " A solution to the optimal power flow using simulated annealing," Electrical Power \& Energy Systems (Elsevier), Vol.25, No.1, pp.47-57, 2003.

[10] Z. L. Gaing, "Particle swarm optimization to solving the economic dispatch considering the generator constraints," IEEE Trans. Power Systems, Vol.18, No.3, pp.1187-1195, 2003.

[11] B. Mahdad, T. Bouktir, K. Srairi, "Optimal power flow for large-scale power system with shunt FACTS using fast parallel GA," The 14th IEEE Mediterranean on Electrotechnical Conference, 2008. MELECON 5-7 May 2008. pp.669-676.

[12] Jacob Robinson and yahya Rahmat-Samii, "Particle swarm optimization in electromagnetics," IEEE Trans. Antennas and propagation, Vol.52, No.2, pp.397-407, February 2004.

[13] Ahmed A. A. Esmin, Germano Lambert-Torres, and A. C. Zambroni de souza, "A Hybrid particle swarm optimization applied to loss power minimization," IEEE Trans. Power Systems, Vol.20, No.2, pp.859866, May 2005.

[14] R. C. Eberhart and Y. Shi, "Particle swarm optimiza- 
tion: developments, applications and ressources," in Proc.2001 Congr. Evolutionary Computation, Vol.1, 2001.

[15] B. Mahdad, T. Bouktir, K. Srairi, "Strategy based PSO for Dynamic Control of UPFC to Enhance Power System Security," Accepted at IEEE Powertech Conference 2009.

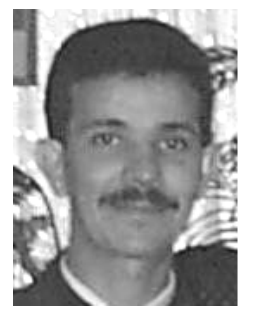

Belkacem Mahdad (S'07) was born in Biskra, Algeria. He received the B.Sc degree in Electrical Engineering (Power system) from Biskra University Algeria in 1990, his M.Sc degree from Annaba University in 2000 . He is currently working towards his $\mathrm{PhD}$ degree in Electrical Engineering from Biskra University, Algeria. His areas of interest are optimal power flow, FACTS Modelling, application of Artificial Intelligence (AI) techniques to FACTS control and improvement in electric power systems. Email: bemahdad@yahoo.fr

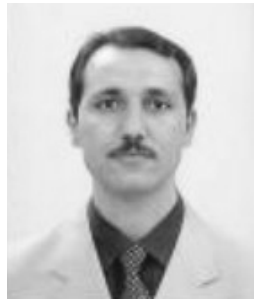

Tarek Bouktir was born in Ras ElOued, Algeria. He received the B.S degree in Electrical Engineering Power System from Setif University (Algeria) in 1994, his MSc degree from Annaba University in 1998, his $\mathrm{PhD}$ degree in power system from Batna University (Algeria) in 2003. His areas of interest are the application of meta-heuristic methods in optimal power flow, FACTS control and improvement in electric power systems, Multi-Objective Optimization for power systems, and Voltage Stability and Security Analysis. He is the executive editor of the journal of Electrical Systems.

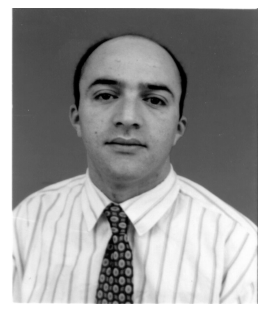

Kamel Srairi was born in Batna, Algeria, in 1967 . He received the B.Sc. degree in Electrical Engineering, in 1991, from the University of Batna, Algeria; the M.Sc. degree in Electrical and Computer Engineering, from the National Polytechnic Institute of Grenoble, France, in 1992; and the Ph.D. degree also in Electrical and Computer Engineering, from the University of Nantes, France, in 1996. After graduation, he joined the University of Biskra, Algeria, in 1998 where he is a Professor in the Electrical Engineering Department. His main research interests include analysis, design, and control of electric systems.

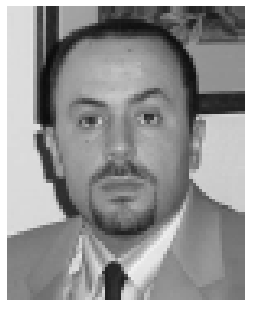

Mohamed El Hachemi Benbouzid (S'92-M'95-SM'98) was born in Batna, Algeria, in 1968. He received the B.Sc. degree in electrical engineering from the University of Batna, in 1990, the M.Sc. and Ph.D. degrees in electrical and computer engineering from the National Polytechnic Institute of Grenoble, Grenoble, France, in 1991 and 1994, respectively, and the Habilitation à Diriger des Recherches degree from the University of Picardie "Jules Verne", Amiens, France, in 2000. After receiving the Ph.D. degree, he joined the Professional Institute of Amiens, University of Picardie "Jules Verne", where he was an Associate Professor of electrical and computer engineering. In September 2004, he was with the University Institute of Technology (IUT) of Brest, University of Western Brittany, Brest, France, as a Professor of electrical engineering. He is currently with the Laboratoire Brestois de Mécanique et des Systèmes, University of Brest. His main research interests and experience include analysis, design, and control of electric machines, variable-speed drives for traction and propulsion applications, and fault diagnosis of electric machines. Prof. Benbouzid is a Senior Member of the IEEE Power Engineering, Industrial Electronics, Industry Applications, Power Electronics, and Vehicular Technology Societies. $\mathrm{He}$ is an Associate Editor of the IEEE TRANSACTIONS ON ENERGY CONVERSION, the IEEE TRANSACTIONS ON INDUSTRIAL ELECTRONICS, the IEEE TRANSACTIONS ON VEHICULAR TECHNOLOGY, and the IEEE/ASME TRANSACTIONS ON MECHATRONICS. 